\title{
Early childhood educator' perspectives on how infants and toddlers learn: Australia and China
}

\author{
M. Li ${ }^{1}$, B. Nyland ${ }^{2 *} \mathbb{D}$, K. Margetts ${ }^{3}$ and Y. Guan ${ }^{1}$
}

\author{
*Correspondence: \\ Berenice.nyland@rmit.edu.au \\ ${ }^{2}$ RMIT University, Melbourne, \\ Australia \\ Full list of author information \\ is available at the end of the \\ article
}

\begin{abstract}
This paper is an exploratory study to identify similarities and differences between two groups of early childhood educator' perceptions of how infants and toddlers learn in the contexts of Australia and China. Researchers have demonstrated the importance of high-quality education programs for children in the first 3 years and evidence now exists that these learning experiences can be enhanced when programs include infant and toddler participatory practices. The concept of participation for infants and toddlers was the focus of the data collection. To investigate educator's perceptions of children's participation in their own learning was the aim of this research with a purpose of conducting a comparative study on the sharing of knowledge, attitudes and practices across the two contexts. The study was based on a theoretical understanding of learning and participation grounded in socio/cultural theories on the importance of context and the social nature of learning. An anonymous survey was conducted with educators working with infants and toddlers in early childhood services in the two countries. Results were similar for many of the survey questions with two significant areas of difference, relationships with parents and the role of creative activities in children's learning. These results have been discussed against the infant/toddler education and care literature and contextual information from both countries. Discussion focuses on educator' perceptions of how children learn and what is participation in these early years. The findings have implications for the training of educators working with infants and toddlers and for the design of early childhood programs for our very youngest.
\end{abstract}

\section{Background}

The purpose of this project was to identify how two groups of early childhood educators, in Australia and China, perceive participation as a significant part of the process of infant and toddler learning in the group care context. This research has implications for the sharing of early childhood education ideas across contexts and the quality of provision for children under-3 years in early childhood and care environments. As a part of an on-going comparative study (Brostrom et al. 2012, 2014) that has undertaken similar research in Denmark, Sweden, Australia, Germany, Estonia, Greece and Russia, in this discussion we explore survey results of Australian and Chinese educator views of how children learn and how they view the role of participation in children's learning. The differing contexts described below are used to frame the discussion about 
pedagogical beliefs and understandings of the Chinese and Australian educators. The paper is grounded in socio/cultural theories on the importance of context and the social nature of learning (Moore and Dunham 1995; Vygotsky 1978) as these are important aspects of participatory learning. The notion of participation in learning was the focus of the design of the questionnaire used in the research. Educators working in group education and care settings with infants and toddlers in Australia and China were asked to complete an anonymous questionnaire with an aim of describing their views of infants and toddlers as learners. The survey had four sections which included questions on the types of situations that provide optimal opportunities for learning, what activities can educators provide to promote learning, what are the best conditions for children to learn and the final set of questions asked about participation and learning. As stated ages of infants and toddlers change depending on the text used in this research, the age of infants is taken as birth-24 months and toddlers 24-36 months (Nixon and Gould 1996).

Increasingly infant-toddler group care is becoming a focus of research (Degotardi and Pearson 2014; Elfer 2006) as the importance of the early years has gained attention in many disciplines, including neuroscience (Shonkoff and Phillips 2001). The benefits of care for the very young are often seen by policymakers as much needed workforce support (Kalil et al. 2012) while others emphasise human capital, lifelong skill development and the importance of investment (Heckman et al. 2013). School readiness has become one of these outcomes as the term 'school readiness' is broadened from a narrow view aligned with academic skills to an expansion of the idea that development is transactional (Horm et al. 2016). Educationalists, who are more influenced by a socio/cultural approach, suggest that the concept of the image of the communicative, competent infant, emerging from constructivist research, like that of Reggio Emilia (Maguire-Fong 2014), should be responded to in the design and practice of group care programs and perhaps a new and specialised pedagogy is necessary (Rockel 2009).

As teacher' beliefs are strongly influenced by life history and their own epistemologies (Brownlee et al. 2011), an exploration of educator' views from closely connected countries, with different socio/cultural, political and historical contexts is significant in terms of beliefs about early childhood education, government concerns about improving the quality of the early childhood workforce and the sharing of professional knowledge across borders.

The paper introduces the Australian and Chinese contexts for infant and toddler education and care as a background to the educators' views on how children learn and how they understand the notion of children's participation in their own learning. Literature on infant and toddler participatory learning is presented, the research project is described and findings and implications discussed. The overall aim of this study was to expand previous research on participatory learning (Brostrom et al. 2012, 2014) to include the Chinese early childhood context. Australia and China have developing relationships in the education sector including early childhood education and an exploration of shared ideas and pedagogies is relevant to the two countries. Both countries have been influenced by international ideas (Qi and Melhuish 2017; Tobin et al. 2009) and through internationalisation of higher education there is a growing partnership in pre-service teacher education between Australia and China ( $\mathrm{Ng}$ and Nyland 2016). The questions addressed are: How do educators in Australia and China understand 
participatory learning for infants and toddlers? Are there significant differences across the two contexts?

\section{The Australian and Chinese contexts for infant-toddler education and care}

The following discussion provides a summary of education and care provision for children under three in Australia and China. The timing of reforms and the emphasis on the preschool years in both settings offer a scenario that shares many commonalities. Curriculum documents, regulations and standards and a growing partnership through international higher education initiatives (e.g. Ng and Nyland 2016) present policy contexts suitable for comparison. Care and education programs in Australia have developed a shared regulatory approach in recent years. Where Australia once had a clear demarcation between childcare and preschool education, this has been impacted by recent reforms that have brought both services together under national legislation. Now in Australia children in the age group birth- 5 years, attending a variety of services, are included under the same regulatory package, the National Quality Framework (NQF) (Australian Children's Education and Care Quality Authority (ACECQA) 2012). In China, the care and education of children in the birth-to-three age group comes under the jurisdiction of the National Health and Family Planning Commission and preschools come under the authority of the Ministry of Education. Some preschools in China are extending their programs to cater for children 2-3 years (Zhu 2009). For children in the preschool years in both countries, there are many similarities in the aims and reforms being introduced by the Australian and Chinese governments.

Infant/toddler care and education in Australia is carried out in a variety of locations. For this study, only staff in long day care (LDC) centres and childcare settings were approached. LDC settings cater for children birth- 6 and receive government funds whether they are private or community based. As stated above, early childhood education and care services come under the Australian NQF which includes legislation, regulations, standards for services to be assessed against and a quality monitoring system. A central part of the quality framework is the curriculum document, Belonging, Being and Becoming: The early years framework for Australia (Department of Education, Employment and Workplace Relations (DEEWR) 2009).

National early childhood education reforms were initiated in 2008 and introduced workforce changes and a quality assessment regime. Structural changes to staff qualifications were to be phased in and staff/child ratios were to be improved. For children under three, the ratio across Australia became one staff member for every four children. This has now been enacted. Under the reforms staff working with infants and toddlers must hold a Certificate 111 level qualification. This is a level 3 on the international standard classification of education scale (ISCED). (UNESCO 2012). The Certificate 111 is a general certificate for children's services and is a foundation qualification for working with children birth-5. The certificate is competency based, requires up to 12 months study, contains 16 days placement with 18 separate units. One unit "Provide care for infants and toddlers" specifically relates to the infant-toddler age group (training.gov.au 2016). The Certificate 111 qualification has been a source of contention with many scholars and experts in the field claiming it provides inadequate training for the complexities of designing care and education programs for the very young (Cheeseman et al. 2015). 
Research suggests educators in Australia have different attitudes to teaching children in the infant/toddler age range and teaching children in the preschool years (Degotardi 2010; Rouse et al. 2012). Historically there has been a care and education divide in Australia. Preschool programs, either stand-alone or delivered in LDCs, are seen as needing a degree-qualified early childhood teacher to design an educational agenda while programs for children under 3 , who are viewed as mainly requiring care, need the certificate qualification. These first 3 years are viewed primarily as a workforce support (Rockel 2009) with the main emphasis on care. The demarcation between care and education should have been nationally addressed with the new curriculum framework which contained an image of children birth-5 as 'learners' (Cheeseman et al. 2015). The tenuous and political nature of social images of infants and toddlers, however, has been emphasised by Cheeseman et al. (2015) who fear that the strong image of infants and toddlers as learners, reflected in the national curriculum framework, may revert to the needy child requiring care. These scholars, who authored the national curriculum document, have evidenced their concerns about education for infants and toddlers by commenting on the current priority given to "workforce policy recommendations for children under 36 months" (p. 38) and query whether a foundational credential like the Certificate 111 "to equip educators to take responsibility for infants' well-being and learning" (p. 39) is sufficient. All Australian participants in this research had either a Certificate 111 or Diploma level education.

China has a rapidly developing preschool system and aims for universal access by 2020 (Zhou 2011). The Chinese reform agenda has been as active as the Australian reform agenda with significant recent initiatives being the 2010 Outline for Medium and Longterm Education Reform and Development (2010-2020) (Zhou 2011). This document led directly to the 2011 Curriculum Standards for Teachers and in 2012 the Kindergarten Teacher Professional Standards (Hu and Cai 2012). The 2011 standards specified national curriculum for pre-service teachers with the standards designed to identify the skills and knowledge education students should acquire from their training. Further detail was added with the Kindergarten Teacher Professional Standards (Pang 2012). This second standards document outlined 62 areas where knowledge and competence are required. One of the underlying messages in the kindergarten teacher standards was that students should be aware of unique Chinese early childhood education characteristics that relate to the Chinese social/cultural/historical context.

However, provision for very young children in China has been mixed. Childcare centres are mainly private, are licensed by the Ministry of Human Resources and have been administered by the National Health and Family Planning Commission since 2013. A recent survey from Shijiazhuang city indicated that practitioners in childcare centres usually have a certificate of 'Babysitter' (育婴师) licensed by the Ministry of Human Resources and Social Security. In private for-profit childcare centres, operated by international/national chains, the survey found that only $62 \%$ of 134 educators had a certificate (Di 2016). These findings agree with Zhu's (2009) report on early childhood educator training across the provinces. Tobin et al. (2009) have suggested that rapid social and economic change in China has been reflected in changing parental expectations for education and care of very young children and this will have an influence on the development of childcare centres and demands on staff. Easing of the one-child policy 
(China Daily 2015) will impact on the need for workforce support, especially in a context where many grandparents, most recently the main carers for the very young (Nyland et al. 2009), are staying in the workforce longer as the age of retirement increases (Wong 2015).

Despite extensive research for children under three there has been little educational attention in relation to provision of programs (Davis et al. 2015; Qi and Melhuish 2017). In recent years, the neuroscience research on early brain development has brought an acknowledgment that children learn from birth. This acknowledgement of the importance of the first 3 years has initiated calls for the integration of nurseries and kindergartens so that early child development (ECD) can become a continuous care and education system for children from birth to age 6 (Zhu 2009). Historically, nurseries and kindergartens have been under the administration of different ministries and the infant-toddler programs have been oriented towards basic health and care. However, growing interest in children and education in the birth-to-three age group has led to government attention and planned changes. Zhu and Zhang (2008) commented on some of the issues that have made the development of education services for children under three difficult:

Two main issues are the separate administration and the lack of resources. The community, parents and the administration at different levels will need to work together to achieve this goal. This integration effort, however, also provides new challenges for early childhood researchers. The longstanding focus on kindergarten children from ages three to six has resulted in a scarcity of studies of younger children's development and care. The early childhood community needs to take on the challenge and devote more resources and effort to exploring models for the successful care and education of children from birth to 3 years of age (p. 179).

Although Zhu and Zhang wrote their paper 8 years ago and despite the reform agenda, which has had an almost exclusive kindergarten focus (Qi and Melhuish 2017) the situation seems similar today. In a presentation at Beijing Normal University (Beijing Normal University Newsletter 2015), Professor Liu Yan reported on the situation for children under three in education and care programs. She made an appeal for regulations to be developed for children birth-3 as the present situation is one where there is a regulatory vacuum, a lack of standards and professional training as well as uneven quality. Given the demand for education and care programs for this age group, she urged the Ministry of Education to develop policies as kindergarten practices were not suitable for children birth-to-three age group. The Chinese participants in this research had qualifications ranging from a high school certificate through to a masters' degree. The latter were directors of services. These are levels three to seven on the ISCED.

\section{Literature review: participation and children's learning in the first $\mathbf{3}$ years}

The early childhood literature on group programs for children under 3 years has had a strong focus on the assumption that children's care and education experiences will be influenced by early childhood educators' theories about infancy (Raikes and Edwards 2009), theories about what and how children should learn (e.g. Ong 2012) and how their life experiences influence these interpretations (Rogoff 2003). Much of the early research on infant and toddler programs treated aspects of providing and planning for children 
prior to school, the years birth-5, as a similar group. Where differentiation was made it was often to do with aspects of provision, like group size (Huntsman 2008). In recent years, however, there has been a growing interest in pedagogical practices for infants and toddlers (e.g. Degotardi and Pearson 2014; Lawrence 2012; Meade et al. 2012) with a position emerging that children in this age group have different ways of establishing relationships and internalising experience (Oliveira-Formoshino and Araújo 2014; White et al. 2014). There is also a growing trend to observe child/child relationships (Greve 2009). Such views have been influential in the learning and participation literature.

Participation has become an issue that has been researched in relation to children's learning in group care contexts. Berthelsen et al. (2009), p. 93) define participation as; "l[L]earning in which toddlers create their own understanding and are active in the processing of information". Nyland (2009) observed infants in childcare over a 3-year period and surmised that the child's own experiences could often be described as participatory observation, which is a style of learning not emphasised in the infant/toddler texts (e.g. Degotardi and Pearson 2014). Another type of learning and participation has been researched by Laevers (2011) in his work on the significance of observing the young child's actions to gain a measure of the child's level of involvement and well-being within a setting. Much of this research contained observations of children's self-motivated play activity, often with objects, not companions. Example studies that have focused on everyday observed events include Brownlee and Berthelsen (2004), Rogoff et al. (1998) and Rolfe et al. (2002). These research projects were based on empirical data, naturalistic observations, to interpret how participation was enacted in specific childcare contexts for infants and toddlers. Findings supported Laevers emphasis on self-directed learning and levels of engagement and involvement in the selected task.

Another aspect of research on infants in group care that makes the learning and participation research complex is the differing theoretical views taken. Elfer (2006) strongly favours attachment theory; White et al. (2014) focus on teacher infant social dialogue; Oliveira-Formoshino and Araújo (2014) emphasise diversity and democratic pedagogy-inparticipation and others employ differing kinds of socio/cultural theory (e.g. Meade et al. 2012). That rights-based practice is beneficial is also argued (Woodhead 2006). The theoretical approach that influences an educator will impact on decisions about daily practice.

A focus of this paper is educator interpretations of how infants' learn in the group care setting. In Australia there have been a number of studies that have examined educators' beliefs and subsequent interactions with young children (e.g., Brownlee et al. 2000; Nyland 2004; Degotardi and Davis 2008; Degotardi 2010). Findings reported a difference between educators' descriptions of children's self-initiated activity and children participating in routine events like nappy change. This difference in the educator's approach to encouraging participation during routine and play sequences emerged as a feature of the research with Degotardi (2010, p. 30) finding that "practitioners' thinking about routine interactions was less complex than their reasoning about play interactions". This is a point supported by Trevarthen (2011, p. 175) when he says of infants in childcare settings:

t[T]he natural creativity and cooperation of infants and toddlers, their self-produced motives for acting and knowing with other people, are given less attention than their needs for care and protection. 
The complexity of working with very young children is acknowledged in the literature and Allen and Kelly (2015) comment on the fragmentation of types of programs provided for young children, the differing staff qualifications that exist and in many cases, especially in the infant-toddler years, staff with minimal training levels. An emphasis on the context is important to this research as children's learning has embedded meaning (Rogoff 2003). The significance of activity in the everyday is emphasised (Hedegaard 2008) by the research questions which focus on optimal contexts that promote children's learning.

Perspectives from educators in Australia and China have been explored as these two countries have developed educational ties across the years. Trained early childhood teachers are on the Australian skills list, and Chinese early childhood professionals are among groups seeking employment in the early childhood field in Australia. Of these some have been trained in China, some in Australia and some have done a combined degree through joint programs (AEI 2015). China is Australia's top source country for international students (Australian Government 2015) and two-way institutional partnerships are growing (AEI 2015).

\section{The research}

\section{Theoretical frame}

The conceptual frame adopted is a socio/cultural approach emphasising the theories of participation and social mediation (Stetsenko 2007; Vygotsky 1978). Learning occurs as children interact with people and objects in their environment. Through their own actions children appropriate the culture of their surroundings (Rogoff 2003). Rogoff explains this happens through guided participation but for the children to internalise and interpret experience they must encounter other members of the culture on a social plane and re-create the experience through an intrapsychological process (Vygotsky 1978). For early childhood educators, these notions of social interaction and guided participation are important. This research project is part of an on-going international comparative project (Brostrom et al. 2012, 2014) that has sought to investigate educator's perceptions on children's learning and their understanding of participation. A single questionnaire was developed to use in each country participating in the research and for this paper we examined surveys from Australian and Chinese practitioners who were working with infants and toddlers.

\section{The questionnaire}

The questionnaire, designed for previous research (Brostrom et al. 2012, 2014), consisted of four key questions consisting of 6-10 items that inquired into some aspect of children's learning and the significance of participation. The four questions covered the following:

- What situations are characteristic of learning?

- What circumstances are important for learning?

- What are preconditions for children's learning?

- How do you understand participation in relation to children's learning? 
Participants were asked to rank each item from 1 to 4 (or N/A if not appropriate) with 1 being the most important, 2 the second most important and so on. The participants were also informed they could give the same number to several items if they chose. The questions and choices offered in the questionnaire are listed in Tables 1, 2, 3 and 4. A frequency distribution with numbers and percentage for participant's responses to each question has been used to indicate the importance of each item. The research questions:

How do educators in Australia and China understand participatory learning for infants and toddlers? Are there significant differences across the two contexts?

Table 1 Situations characteristic of learning: responses from infant/toddler educators

\begin{tabular}{|c|c|c|c|c|c|c|}
\hline & \multicolumn{3}{|c|}{ Australia } & \multicolumn{3}{|l|}{ China } \\
\hline & Rank & M & $\%$ & Rank & M & $\%$ \\
\hline Play where children and adults participate together & 1 & 1.38 & 69.7 & 4 & 1.59 & 48.1 \\
\hline Situations which build on children's own initiatives & 2 & 1.53 & 63.6 & 3 & 1.54 & 59.3 \\
\hline Situations which contribute to children's social development & 3 & 1.55 & 60.6 & 5 & 1.65 & 48.1 \\
\hline Free play & 4 & 1.58 & 48.5 & 6 & 2.07 & 35.2 \\
\hline Creative activities, for example, painting and music & 5 & 2.00 & 33.3 & 1 & 1.35 & 70.4 \\
\hline Conflicts in everyday life which children try to solve themselves & 6 & 2.26 & 42.4 & 2 & 1.43 & 63.0 \\
\hline Goal-directed activity in order to develop reading and writing & 7 & 2.72 & 21.2 & 8 & 2.48 & 24.1 \\
\hline Circle time & 8 & 2.81 & 21.2 & 7 & 2.17 & 27.8 \\
\hline
\end{tabular}

Table 2 Circumstances important for learning: responses from infant/toddler educators

\begin{tabular}{|c|c|c|c|c|c|c|}
\hline & \multicolumn{3}{|c|}{ Australia } & \multicolumn{3}{|l|}{ China } \\
\hline & Rank & $M$ & $\%$ & Rank & $M$ & $\%$ \\
\hline Participating in a variety of activities across the day & 1 & 1.21 & 78.8 & 1 & 1.63 & 53.7 \\
\hline Playing with other children & 2 & 1.53 & 48.5 & 5 & 1.80 & 44.4 \\
\hline Self-initiated activities & 3 & 1.70 & 48.5 & 2 & 1.72 & 51.9 \\
\hline Participating in activities with adults & 4 & 1.77 & 36.4 & 3 & 1.67 & 51.9 \\
\hline Seeing what other children do and say & 5 & 1.80 & 48.5 & 6 & 1.76 & 40.7 \\
\hline Seeing what adults do and say & 6 & 1.81 & 51.5 & 7 & 1.91 & 40.7 \\
\hline The child being absorbed in own interest & 7 & 1.84 & 51.5 & 8 & 2.22 & 25.9 \\
\hline Adults teaching by explanation and modelling & 8 & 1.84 & 45.5 & 4 & 1.85 & 46.3 \\
\hline Being challenged by adults & 9 & 1.87 & 27.3 & 9 & 2.26 & 24.1 \\
\hline The child being allowed to be left in peace and quiet & 10 & 2.60 & 18.2 & 10 & 2.54 & 11.1 \\
\hline
\end{tabular}

Table 3 Preconditions for learning: responses from infant/toddler educators

\begin{tabular}{|c|c|c|c|c|c|c|}
\hline & \multicolumn{3}{|c|}{ Australia } & \multicolumn{3}{|c|}{ China } \\
\hline & Rank & $M$ & $\%$ & Rank & $M$ & $\%$ \\
\hline Educators are in active interaction with children and support them & 1 & 1.23 & 72.7 & 3 & 1.33 & 66.7 \\
\hline Children experience respect and security from adults & 2 & 1.28 & 75.8 & 1 & 1.17 & 83.3 \\
\hline Educators create conditions for children's well-being & 3 & 1.38 & 69.7 & 4 & 1.37 & 66.7 \\
\hline There is good cooperation with parents & 4 & 1.56 & 54.5 & 2 & 1.33 & 72.2 \\
\hline Children must meet challenges adjusted to their level of development & 5 & 1.66 & 48.5 & 5 & 1.78 & 48.1 \\
\hline Children get many experiences & 6 & 1.67 & 63.6 & 7 & 1.98 & 42.6 \\
\hline Children's own choices without adult intervention & 7 & 1.93 & 39.4 & 6 & 1.78 & 44.4 \\
\hline
\end{tabular}


Table 4 What is participation? Responses from infant/toddler educators

\begin{tabular}{|c|c|c|c|c|c|c|}
\hline & \multicolumn{3}{|c|}{ Australia } & \multicolumn{3}{|l|}{ China } \\
\hline & Rank & $M$ & $\%$ & Rank & $M$ & $\%$ \\
\hline Educators listen to children and understand their way of thinking & 1 & 1.22 & 75.8 & 5 & 1.35 & 72.2 \\
\hline Educators encourage children to make their own decisions & 2 & 1.33 & 69.7 & 4 & 1.28 & 75.9 \\
\hline To have influence on what happens & 3 & 1.77 & 45.5 & 7 & 2.09 & 22.2 \\
\hline Educators make up best conditions for children's independent choice & 4 & 1.77 & 45.5 & 3 & 1.31 & 77.8 \\
\hline To be involved in current activities & 5 & 1.83 & 45.5 & 6 & 1.48 & 55.6 \\
\hline To listen & 6 & 2.00 & 36.4 & 1 & 1.20 & 87.0 \\
\hline To be part of a group and enter into its activities being together & 7 & 1.17 & 33.3 & 2 & 1.24 & 79.6 \\
\hline
\end{tabular}

\section{The participants}

The questionnaires in Australia were administered in childcare settings in the state of Victoria, Australia. The sample selection was based on previous Australian research in this study, and access and ethics approval had been arranged for centres in Victoria. 33 early childhood educators working with children under 3 responded. This was the first time China had joined this comparative research team and sampling was conducted through networks and associations. In the cases of both countries, the target audiences were representative; participation was voluntary and therefore participants were selfselected. In China 104 educators working with children under 3 responded across a number of provinces. The following table gives a breakdown of the participants according to the age of the educator and qualification level, year of completing study and years of experience (Table 5).

Table 5 indicates that half the Australian educators were aged between 20 and 39 years. Of the other half, most were between 40 to 49 years with 2 over 50 . Infant-toddler educators who had worked with children for more than 20 years were more likely to recently have qualified or recently upgraded their qualifications. This can be explained by recent reforms in Australia under the National Quality Framework (Australian Children's Education and Care Quality Authority (ACECQA) 2012) which requires qualifications for all staff and upgrades of minimal level qualifications, especially for staff in the infant/toddler rooms. The Chinese participants present quite a comparison to their Australian counterparts. They were much younger on the whole, with the majority under 29. They had considerably less experience but tended to be better qualified. The qualifications were compared using the ISCED descriptors with a Certificate 111 in Australia matching estimated time of study and levels with the Chinese high school certificate at level 3 on the ISCED. The Australian cohorts were qualified at levels 3 and 5, while the Chinese cohort covered levels 3-7.

In Australia, the Productivity Commission has set the qualification for practitioners working with children birth-2 at Certificate 111 level (Goodstart Early Learning 2015). In China there is a growing demand for regulations and policy development for children in the first 3 years but no national guidelines have been promulgated. The high school certificate as a qualification is steadily being phased out (Fan et al. 2016). The survey in this research was directed at educators and the Australian profile is representative of staff working with children in infant/toddler nurseries. The higher qualifications of some 


\begin{tabular}{|c|c|c|c|c|}
\hline & \multicolumn{2}{|c|}{ Australia } & \multicolumn{2}{|c|}{ China } \\
\hline & $\mathrm{n}$ & $\%$ & $\mathrm{n}$ & $\%$ \\
\hline \multicolumn{5}{|l|}{ Age range } \\
\hline$<24$ & 0 & 0 & 25 & 24.03 \\
\hline $24-29$ & 8 & 24.2 & 50 & 48.07 \\
\hline $30-39$ & 9 & 27.3 & 28 & 26.9 \\
\hline $40-49$ & 14 & 42.4 & 1 & 0.9 \\
\hline $50-63$ & 2 & 6.0 & 0 & 0 \\
\hline \multicolumn{5}{|l|}{ Years of experience } \\
\hline$\leq 1$ & 0 & 0 & 23 & 22.1 \\
\hline $2-5$ & 3 & 9.1 & 42 & 40.4 \\
\hline $6-9$ & 7 & 21.2 & 21 & 20.2 \\
\hline $10-19$ & 14 & 42.4 & 11 & 10.6 \\
\hline$\geq 20$ & 9 & 27.3 & 7 & 6.7 \\
\hline \multicolumn{5}{|l|}{ Qualifications } \\
\hline ISCED level 3 Certificate 3 or equiv. & 26 & 78.8 & 21 & 20.2 \\
\hline ISCED level 5 Diploma, Assoc. Degree or equiv. & 7 & 21.2 & 44 & 42.3 \\
\hline ISCED level 6 Bachelor or equiv. & 0 & 0 & 32 & 30.8 \\
\hline ISCED level 7 Master or equiv. & 0 & 0 & 7 & 6.7 \\
\hline \multicolumn{5}{|l|}{ Year of qualification } \\
\hline 1970-1979 & 0 & 0 & 0 & 0 \\
\hline 1980-1989 & 0 & 0 & 3 & 2.9 \\
\hline 1990-1999 & 6 & 18.8 & 14 & 13.6 \\
\hline $2000-2009$ & 11 & 34.4 & 26 & 25.2 \\
\hline 2010-2015 & 15 & 46.9 & 60 & 58.3 \\
\hline Missing & 1 & 3 & 1 & 1 \\
\hline
\end{tabular}

Chinese participants are explained because these were staff in leadership positions. Participation was voluntary, the questionnaire was anonymous and directed to relevant early childhood educator populations so it was not possible to control for the differences that emerged. However, the responses to the questionnaire suggested all participants shared an understanding of infant/toddler pedagogy and were able to express their own ideas about participatory learning in the target age group.

\section{Results from the questionnaire}

In this section of the paper, we report on each of the four sections of the questionnaire. The intent of each question is identified; a summary table is provided to indicate the importance of an item.

Question 1. What situations are characteristic of learning? The situations listed on the questionnaire were concerned with the types of activities children will be engaged in across the day and which ones might best promote learning. The first question was designed to explore educators' ideas of which types of situations they most identified as activities with characteristics where learning was most likely to occur. The results can be seen in the following table (Table 1). 
For the Australian infant/toddler educators 'play where children and adults participate together' was most frequently considered most important, followed by 'situations which build on children's own initiatives', 'situations which contribute to children's social development' and 'free play' as an important situation for learning. For the Chinese educators 'situations which build on children's own initiatives', 'conflicts in everyday life which children try to solve', 'creative activities and situations which contribute to children's social development' were most frequently rated. Across the two groups of participants, goaldirected activities related to reading and writing and circle time were the least likely to be rated as most important situations to characterise learning. These results suggest a shared belief that formal didactic activities are not suitable for children in this age range. Such a view is supported in the international literature (Nutbrown and Page 2009).

Question 2. What circumstances are important for learning? This part of the questionnaire had a major focus on participation including: institutional participation where the predominant belief in children's learning is that it occurs in a shared social process, such as 'participating in a variety of activities across the day'; social interaction, was emphasised in the categories 'playing with other children', 'participating in activities with adults'; participatory observation, when the child is 'seeing what other children do', 'seeing what adults do' and intentional teaching, with 'adults teaching by explanation and modelling' and 'when the child is being challenged by the adult'. The last category 'the child being allowed to be left in peace and quiet' could relate to levels of participation from the viewpoint of the child's own self-directed involvement and well-being.

The infant and toddler educators were asked to evaluate the most important circumstances for children's learning and rank them. Table 2 reports the percentage of the 'most important' items. The greater percentage of the educators in the Australian sample rated three items as 'most important' and these were; 'participate in different activities in everyday life in the early childhood institution', 'playing with other children,' 'self-initiated activities. The Chinese educators were in agreement on the first choice and close on 'self-initiated activities'. Both groups placed 'the child being allowed to be left in peace and quiet' last.

Question 3. What are preconditions for children's learning? This question was concerned with the adult role in providing for children and encouraging participation in active learning. The first 6 categories look at some aspect of adult support and it is only the 7th category 'children's own choices without adult interference' that provides for the type of agency that would link to a broader view of democracy in the institution (Moss 2009a, b). Both groups most frequently rated this category least important.

The pattern of ratings between the two groups of educators differed somewhat for this question with the Chinese educators emphasising the idea of cooperation with parents.

The Australian cohort listed the parent option as 4th while the Chinese group rated it at number 2. The Australian group again placed a greater value on the adult being actively involved in interactions with children, number 1, and placed child choice without adult intervention last. There was agreement about children being challenged but with appropriate challenges planned according to developmental levels. 
Question 4. How do you understand participation in relation to children's learning? This fourth question was designed to find out what beliefs the educators might have about the notion of participation, how the ideas of the concept of participation would influence answers given to the first three questions of the questionnaire and how these perceptions might influence practice.

'To be part of a group and enter into its activities being together' was least popular for the Australian infant/toddler group of educators, while this was number 2 for the Chinese group. These different positions could be linked to perceptions about infancy itself. This surmise is supported by the responses the educator groups gave to the two categories that related to listening to children. The proactive category of 'to listen' was favoured by the Chinese group but not favoured by the Australian group. The more controlled 'educators listen to children and understand their way of thinking' was the first ranked answer for the Australian educators which raises questions of reciprocity and agency for infants and toddlers within the childcare environment. The Chinese educators again emphasised the importance the group.

\section{Discussion}

From the questionnaire, the picture that emerges of the Australian educators is one of mixed age and years of experience with qualifications at the lower end of the ISCED table. The most popular answers to questions were nuanced with often a less powerful image of the child being expressed in the choices made. An example of this was in Table 1 where 'Play where children and adults participate together' was chosen above the more expansive 'Situations which contribute to children's social development' while 'Situations which build on children's own initiatives' was privileged over the more classic situation of 'Free play'. There was a strong emphasis on the role of the adult where the educator was seen as a participant in children's play, while playing with other children was important being part of a group was not considered to be necessary for participatory learning.

The Chinese educators expressed many similar views to the Australian group, especially in relation to formal goal-directed and circle time activities. There was also close agreement on children needing adult intervention to support choices. They placed an emphasis on participation in a variety of experiences supplied to children in relation to children's learning while being less sanguine about 'many experiences', as a precondition for learning. The choice of 'creative' activities for the first question suggested a pedagogical difference. One explanation is that these educators were trained early childhood staff but as there is no specialist training for those working with children under three in China preschool pedagogies might be privileged (Liu 2015). Although the difference was often not significant between the two groups on individual questions, overall the Chinese educators considered group membership more important than the Australians so that the ability to manage conflict and to be part of a group were more important for the Chinese group and this pattern supports the value given to cooperating with parents that the Chinese educators scored more highly than the Australians. These differences could be further explored by examining the cultural and social backgrounds of the educators. The Chinese educators may favour the group because of the importance of 
collectivist groups, like the family, in Chinese culture. The Australian training regime is likely to be more influenced by American individualism.

The first question asked in this paper was: How do educators understand participatory learning for infants and toddlers? From the responses to the questionnaire we can conclude that the infant/toddler educators had similar understandings of learning and participation given the number of rankings that were similar. Given the emphasis on the adult role as interactive, or even interventionist, there is the implication that many of the activities across the day would be adult-designed activities and for the younger children probably involve many routines. That 'children's own choices without adult intervention' was least frequently given a rating of most important supports the idea that for infants and toddlers levels of choice, reciprocity and having an active voice and opinion may be limited for both groups. The focus in this research related to ideas of participation in learning, and these are influenced by educator's theories of infants which will in turn dictate what happens during the day.

The literature reviewed supports an idea that there is an increasing understanding of how infant/toddler educators' beliefs about infants and the nature of learning and participation (Berthelsen et al. 2009) will influence practice in respect to interactions, daily scheduling of activities and levels of choice. In other words the extent to which participatory learning is an active component within the environment. Many researchers examining the infant world of group care portray a child that is capable of active participation, is communicative and can 'voice' an opinion. Relationships are important as the child can observe power relations and also share reciprocal relationships within a specific context. There is increasing research into infant relationships with other infants. In the light of the survey result that found 'The child should have the right to be alone and be able to make choices without adult intervention, or guidance' not important for either group raises an issue that can be investigated in relation to the literature on participation and rights (Woodhead 2006). The responses to this first question suggest in both the Chinese and Australian group context that care is still considered more important for children under three than education. In the Australian context, formal care is more widespread for children in this age group and the similarity in responses suggest that in terms of infants and toddlers participatory learning, all educators favoured planning and levels of control as a pedagogic strategy.

The second question concerned the idea of: Are there significant differences across the two contexts?

The two areas where significant differences were present were those of characteristics of the two groups in relation to qualifications, age and experience and from the Chinese group there emerged a pattern of answers to suggest that group membership was more important to this cohort than the Australian group. The question of group membership and working with parents emerged as a difference in the study. The group membership emphasis from the Chinese participants could be related to the social, political and economic importance of the family in Chinese culture. The importance of belonging to the family group, scholars like Huang (2011) suggest, is an integral part of Chinese history and the relationships and structures that exist in the Chinese family cannot be explained using conventional western insights. These differences potentially have implications in 
terms of government policy, training and cultural practice while at the same time the shared understandings of the educator role across the two contexts were striking.

\section{Implications}

Government policy and the regulatory environment will drive the qualifications needed to be employed as an educator in the early childhood education and care sector. Both countries have reform agendas in place to build provision for early childhood services, improve quality and make services more accessible. The joint purpose of care and education has created confusion in terms of some policies in the early childhood years. In China, the context discussed at the beginning of this paper suggests that the birth-tothree age group has not yet received appropriate regulatory recognition. For Australia, there has been disappointment amongst advocates for quality provision of services as government policy has backed away from promoting the need for higher qualifications for those working with the very youngest. In both countries, there is a perceived need that the care and education services for children birth-3 years should be supported by developing staff with appropriate specialist skills, given the importance of these early years (Liu 2015; Cheeseman et al. 2015).

How might practitioner' views of children's learning influence their practice? From the first question of the survey we can argue that an adult-dominated model of care and education for infants and toddlers would appear to take precedence over self- initiated play and discovery learning suggesting the educators see intervention as an important part of their role during these early years where children learn language and culture. This point is supported by the answers to the questionnaire in the participation section, question four. Test (2006) discusses how infant/toddler educators, through symbolic and cultural mediation 'teach' children how to be members of the culture. Understanding of participation and the importance of guided participation through social interactions was not strongly present in answers from the Australian and Chinese educators. This has implications for educator training and the design of early childhood programs. Both the Chinese and Australian groups were trained to work as educators in early childhood services with the Chinese group being younger and more highly qualified. This Chinese group had no specialist training in working with children birth-3 years which is compulsory for the Australian educators. The presence of specialist training for the Australian group did not appear to resonate in the results of the survey suggesting it was:

1. not effective, or,

2. the Chinese educators could use their higher levels of education to approach their work in a more critical way, or,

3. there is little acknowledgement in early childhood educator training yet of the literature that suggests children of this age group require a different pedagogical approach to preschool children (Rockel 2009).

The third implication to emerge from the survey results was around the question of local and global knowledge and practices. All participants indicated a sound acquaintance of international knowledge of working with young children. Similarities in many 
rankings support this statement as well as the types of answers where the concordance occurred.

The difference indicated in the Chinese emphasis on group belonging could be representative of an expression of Chinese social values. Pang (2012) discussed the idea that the Chinese kindergarten teachers' professional standards were to develop high-quality practice and also to promote Chinese early childhood education characteristics. The history of early childhood services in the two countries across the twentieth century converged and diverged at different times. The early kindergartens were influenced by the Froebel movement in both countries, early Chinese theorists like Chen Heqin were followers of John Dewey, China then experienced revolution and a strong Soviet influence (Vong 2009). Since 1978 theorists like Piaget and Vygotsky have been popular in both contexts. Hsueh et al. (2004) suggest China is building bridges between colonialism, communism and the present. The idea, therefore, of a collective society that emerges from these tensions will have a mix of influences and practices that reflect this combination. Australia is a former British colony and now a multicultural country that is influenced heavily by American and European ideas. The similarities and differences discussed here are examples of many shared educational ideals and theoretical knowledge that represent internationalisation of early childhood education.

The Chinese educators, however, display a sense of group belonging that would support Vygotsky's views of the individual within the group and the paramount importance of the role of social context for children's learning. These differences are nuanced and may be valuable sites of inquiry as government early childhood reform agendas are designed to connect local and global ideas to best advantage.

Authors' contributions

ML collected the Chinese data and assisted with drafting the article; BN collected the Australian data and drafted the article; KM analysed the Australian data and YG analysed the Chinese data. All authors read and approved the final manuscript.

\section{Author details}

${ }^{1}$ Beijing Normal University, Beijing, China. ${ }^{2}$ RMIT University, Melbourne, Australia. ${ }^{3}$ University of Melbourne, Melbourne, Australia.

\section{Authors' information}

A/P Li is an academic at Beijing Normal University. She specialises in comparative studies and early childhood policy. She has recently been an editor of a book with Springer, Contemporary issues and challenge in early childhood education in the Asia-Pacific region. A/P Nyland is an academic at RMIT University. She has researched early childhood issues in China for over a decade, has an on-going partnership with colleagues at Beijing Normal University and has published widely in international journals. A/P Margetts is an honorary fellow at the University of Melbourne. She is a well-known author of practitioner texts for early childhood students and has been involved in comparative research for a number of years. Ms Guan is completing a thesis in early childhood education at Beijing Normal University.

\section{Acknowledgements}

Not applicable.

Availability of data and materials

Information is given in main text of the paper. The survey questions supplied details of participants and results. The raw data are stored at RMIT University and Beijing Normal University.

\section{Funding}

Not applicable.

\section{Publisher's Note}

Springer Nature remains neutral with regard to jurisdictional claims in published maps and institutional affiliations. 


\section{References}

Allen, L., \& Kelly, B. (Eds.). (2015). Transforming the workforce for children birth through age 8: A unifying foundation. Washington: National Academies Press.

Australian Children's Education and Care Quality Authority (ACECQA) (2012). National Quality Framework. http://www. acecqa.gov.au/national-quality-framework. Accessed 22 Oct 2017.

Beijing Normal University Newsletter, (2015). Representatives attend the 12th national people's congress and CPPCC national committee meeting. http://english.bnu.edu.cn/universitynews/77855.htm. Accessed 22 Oct 2017.

Berthelsen, D., Brownlee, J., \& Johannson, E. (2009). Participatory learning in the early years: Research and pedagogy. New York: Routledge.

Brostrom, S., Sandberg, A., Johansson, I. \& Frokjaer, T. (2012). Preschool teachers' view on learning in preschool in Sweden and Denmark. European Early Child Education Research Journal, doi:10.1080/1350293X.2012.746199.

Brostrom, S., Sandberg, A., Johansson, I., Margetts, K., Nyland, B., Frokjaer, T. Kieferle, C., Seifert, A., Roth, A., Ugaste, A. \& Vrinioti, K. (2014). Preschool teachers views' on children's learning: An international perspective. Early Child Development and Care. doi:10.1080/03004430.2014.958483.

Brownlee, J., \& Berthelsen, D. (2004). Working with toddlers in child care: Personal epistemologies and practice. European Early Childhood Education Research Journal, 12(1), 55-70.

Brownlee, J., Petriwskyj, A., Thorpe, K., Stacey, P., \& Gibson, M. (2011). Changing personal epistemologies in early childhood pre-service teachers using an integrated teaching program. Higher Education Research and Development, 30(4) $477-490$

Cheeseman, S., Sumsion, J., \& Press, F. (2015). Infants of the productivity agenda: Learning from birth or waiting to learn. Australasian Journal of Early Childhood, 40(3), 97-105.

China Daily, (2015). China denies immediate validity of two one child policy. http://www.chinadaily.com.cn/china/201511/02/content_22345751.htm. Accessed 22 Oct 2017.

Davis, B., Torr, J., \& Degotardi, S. (2015). Infants and toddlers: How visible are they in the early years framework. International Journal of Child Care Education Policy, 9, 12. doi:10.1186/s40723-015-0014-y.

Degotardi, S. (2010). High quality interactions with infants: Relationships with early childhood practitioners'interpretations and qualification levels in play and routine contexts. International Journal of Early Years, 18(1), 27-41.

Degotardi, S., \& Davis, B. (2008). Understanding infants characteristics and early childhood practitioners' interpretations of infants and their behaviours. Early Years, 28(3), 221-234

Department of Education, Employment and Workplace Relations (DEEWR). (2009). Belonging, being and becoming: An early years learning framework for Australia (EYLF). Canberra: Australian Government.

Di, H. (2016). A survey on educators' quality in childcare centers in Shijiazhuang City. A master thesis to Hebei Normal University (in Chinese). Retrieved from CNKI database.

Elfer, P. (2006). Exploring children's expressions of attachment in nursery. European Early Childhood Education Research Journal, 14(2), 81-95.

Fan, X., Nyland, B., Zeng, X. (2016). What knowledge and skills do Chinese kindergarten, teachers need in a time of reform: Director's perspectives. Asia Pacific Journal of Early Childhood Education Research. (In press)

Goodstart Early Learning (2015). Key recommendations made by the Productivity Commission. https://www.pc.gov.au/ inquiries/completed/education-workforce-earlychildhood/submissions/sub034.pdf. Accessed 22 Oct 2017.

Greve, A. (2009). Friendships and participation among young children in a Norwegian kindergarten. In J. Brownlee, D. Berthelsen, \& E. Johnansson (Eds.), Participatory learning and the early years (pp. 78-92). New York: Routledge.

Heckman, J., Pinto, R., \& Savelyev, P. (2013). Understanding the mechanisms through which an influential early childhood program boosted adult outcomes. American Economic Review, 103(6), 2052-2086.

Hedegaard, M. (2008). Children's development from a cultural-historical approach: Children's activity in everyday local; settings as foundation for their development. Mind, Culture and Activity, 16(1), 64-82.

Horm, D., Norris, D., Perry, D., Chazan-Cohen, R. \& Halle, T. (2016). OPRE report. https://www.acf.hhs.gov/sites/default/files/ opre/opre_nitr_school_readiness_report_v05cover_title.pdf.

Hsueh, Y., Tobin, J., \& Karasawa, M. (2004). Schooling for early childhood: The Chinese kindergarten in its adolescence. Prospects, 34(4), 457-469.

$\mathrm{Hu}$, H., \& Cai, Y. (2012). Development of curriculum standards for teacher education: Processes and issues. Global Education, 41(6), 10-21.

Huang, P. (2011). The modern Chinese family: In the light of economic and legal history. Modern China, 37(5), 459-497.

Huntsman, L. (2008). Literature review: Determinants of quality in child care: A review of the research evidence. http:// www.community.nsw.gov.au/_data/assets/pdf_file/0020/321617/research_qualitychildcare.pdf. Accessed 22 Oct 2017.

Kalil, A., Haskins, R., \& Chesters, J. (Eds.). (2012). Investing in children: Work education and social policy. Washington: Brookings Institution Press.

Laevers, F. (2011). Experiential education: Making care and education more effective through well-being and involvement. Encyclopedia of education and child development. CEECD/SKC-ECD. pp. 1-5.

Lawrence, R. (2012). Pedagogical companionship: Supporting the thinking of others. The first years Ngä Tau Tuatahi, 14(2), $34-39$.

Liu, Y. (2015). The state of early childhood development in China. Keynote address, China Development Research Foundation (CDRF). February.

Maguire-Fong, M. (2014). Teaching and learning with infants and toddlers: Where meaning making begins. New York: Teachers College Press.

Meade, A., Stuart, M., \& Williamson, J. (2012). A study of teachers' work in providing quality care and education for infants and toddlers. The first years Ngä Tuatahi, 14(2), 25-34.

Moore, C., \& Dunham, P. (1995). Joint attention: Its origins and role in development. Hillsdale: Erlbaum.

Moss, P. (2009a). There are alternatives! Markets and democratic experimentalism in early childhood education and care. Working paper 53. Bernard van Leer Foundation. file:///C:/Users/cnyland/Downloads/There_are_alternatives_Markets_and_democratic_experimentalism_in_early_childhood_education_and_care.pdf. 
Moss, P. (2009b). Structures, understandings, and discourses: Possibilities for re-envisioning the early childhood worker. Contemporary Issues in Early Childhood, 7(1), 30-41.

Ng, J., \& Nyland, B. (2016). Internationalisation and global learning. In T. Barkarsas \& A. Bertram (Eds.), Global learning in the 21st century (pp. 231-251). Rotterdam: Sense Publishers.

Nixon, D., \& Gould, K. (1996). Emerging: Child development in the first three years. Sydney: Social Science Press.

Nutbrown, C., \& Page, J. (2009). Working with babies \& children: From birth to three. London: Sage.

Nyland, B. (2004). The Australian child-care centre as a developmental niche. Journal of Australian Research Early Childhood Education, 11(2), 27-39.

Nyland, B. (2009). The guiding principles of participation: Infant, toddler groups and the United Nations convention on the rights of the child. In J. Brownlee, D. Berthelsen, \& E. Johansson (Eds.), Participatory learning and the early years (pp. 26-43). New York: Routledge.

Oliveira-Formoshino, J., \& Araújo, S. (2014). Early education for diversity: Starting from birth. In S. Rayna \& F. Laevers (Eds.), Understanding the under $3 \mathrm{~s}$ and the implications for Education (pp. 1-13). Oxon: Routledge.

Ong, F. (Ed.). (2012). Infant/toddler learning and development program guidelines. Sacromento: Californian Department of Education.

Pang, L. (2012). The background guiding ideology and basic characteristics of the kindergarten teachers' professional standards. Studies in Preschool Education, 7, 3-6.

Qi, X., \& Melhuish, E. (2017). Early childhood education and care in China: History, current trends and challenges. Early Years: International Research Journal, 37(3), 268-284.

Raikes, H., \& Edwards, C. (2009). Extending the dance: Enhancing attachment and relationships. Sydney: Paul Brookes Publishing Co.

Rockel, J. (2009). A pedagogy of care: Moving beyond the margins of managing work and minding babies. Australasian Journal of Early Childhood, 34(3), 1-8.

Rogoff, B. (2003). The cultural nature of human development. New York: Oxford University Press.

Rogoff, B., Mosier, C., Mistr, J., \& Goncu, A. (1998). Toddler's guided participation with their caregivers in cultural activity. In M. Woodhead, K. Faulkner, \& K. Littleton (Eds.), Cultural worlds of early childhood (pp. 230-253). New York: Open University.

Rolfe, S., Nyland, B., \& Morda, R. (2002). Quality in infant care: Observations on joint attentions. Journal of Australian Research in Early Childhood Education, 9(1), 86-96.

Rouse, L., Morrisey, A., \& Rahimi, M. (2012). Problematic placement: Pathways pre-service teachers' perspectives on their infant/toddler placement. Early Years, 32(1), 87-98.

Shonkoff, J. \& Phillips, D. (2001). From neurons to neighborhoods: The science of early childhood development. New York: National Academies Press.

Stetsenko, A. (2007). Being-through-doing: Bakhtin and Vygotsky in dialogue. Cultural Studies of Science Education, 3, 465-485.

Test, J. (2006). Infants and toddlers as transmitters of culture. International Journal of Early Childhood, 38(1), 47-63.

Tobin, J., Hsueh, Y. \& Karasawa, M. (2009). Preschool in three cultures revisited. Chicago: University of Chicago Press.

Training.gov.au (2016). Qualificaton details: CHC307-12: Certificate 111 in Children's Services. https://training.gov.au/Training/ Details/CHC30708. Accessed 22 Oct 2017.

Trevarthen, C. (2011). What young children give to their learning, making education work to sustain a community and its culture. European Early Childhood Education Research Journal, 19(2), 173-193.

UNESCO (2012). International standards of Classification for Education, 2011. http://uis.unesco.org/sites/default/files/documents/international-standard-classification-of-educationisced-2011-en.pdf. Accessed 22 Oct 2017.

Vong, K. (2009). Evolving creativity: New pedagogies for young children in China. Stoke-on-Trent: Trentham.

Vygotsky, L. (1978). Mind in society. Massachusetts: Harvard University Press.

White, J., Peter, M., \& Redder, B. (2014). Infant and teacher dialogue in education and care: A pedagogical imperative. Early Childhood Research Quarterly, 30(A), 160-173.

Wong, C. (2015). China sets timeline for first change to retirement age since 1950s. China Real Time Report (CRT). https:// blogs.wsj.com/chinarealtime/2015/03/10/china-sets-timeline-for-first-change-toretirement-age-since-1950s/. Accessed 22 Oct 2017.

Woodhead, M. (2006). Changing perspectives on early childhood: Theory, research and policy: Background paper prepared for Education for all: Global monitoring report 2007, strong foundations: Early childhood care and education. Paris: United Nations Educational, Scientific and Cultural Organization.

Zhou, X. (2011). Early childhood education policy and development in China. International Journal of Care and Education Policy, 5(1), 29-39.

Zhu, X. (2009). Early childhood education and relative policies in China. International Journal of Childcare and Education Policy, 3(1), 51-60.

Zhu, J. \& Zhang, J. (2008). Contemprary trends and development in early childhood education in China. Early Years: An International Research Journal, 28(2), 173-182. 